\title{
Leprosy: Need Early Detection And Early Treatment
}

\author{
Khondker L ${ }^{1}$, Wahab MA², Khan MSI${ }^{3}$, Hazra SC ${ }^{4}$
}

\begin{abstract}
Leprosy is the most ancient bacterial disease in the history of mankind. It remains still public health problem in the countries where it is endemic. Leprosy (Hansen's disease) is a chronic infectious disease which is diagnosable and curable if recognized early and treated adequately. The infectious agent of leprosy is Mycobacterium leprae which is only bacteria to infect peripheral nerves. Leprosy is characterized by a variety of abnormal immune response. It depends on the integrity of the host's specific CMI response to the M. leprae and it may be genetically determined. Antileprotic multidrugs therapy (MDT) as recommended by WHO is now the standard and accepted method for leprosy control. Leprosy can not be completely rooted out with physicians, control offices, leprosaria and propaganda; it will disappear when the economic and cultural factors change, because leprosy is the thermometer of civilization.
\end{abstract}

Key words: Leprosy, granulomatous diseases.

\section{Introduction}

Leprosy (Hansen's disease) is a chronic infectious disease that primarily affects the peripheral nerves, skin, upper respiratory tract mucosa, eyes and certain other tissues ${ }^{1}$. The causative agent is mycobacterium leprae which is first identified in 1873 by the Norwegian bacteriologist, Gerhard Henrik Armauer Hansen. It occurs at all ages but more common in between $10-20$ and in 30-60 years. The ratio of male and female is $2: 1$ and common in India, Brazil, Indonesia, Myanmar, Madagascar, Nepal, Bangladesh, Thailand, Sub-Sahara Africa and Central America. The prevalence in Bangladesh is $0.29 / 10000$ populations and endemic zones are: Nilphamari1.61 per 10000 populations, Bandarban-1.58 per 10000 populations, Gaibandha-1.56 per 10000 populations and Khagrachari-1.32 per 10000 populations ${ }^{2}$. It is not a hereditary disease. Infection may be genetically determined and monozygotic twins have $60-85 \%$ chance of leprosy ${ }^{3}$. The disease is more common in low socio-economic status, over crowding, poor nutrition and sanitation ${ }^{4}$. The infectious agent of leprosy is Mycobacterium leprae which is obligate

1. Corresponding Author:

Dr. Lubna Khondker, MBBS, MPH,DDV,MCPS, FCPS Assistant Professor, Dept of Dermatology and Venereology Bangabandhu Sheikh Mujib Medical University, Dhaka. E-mail: lubna_derma@yahoo.com.

2. Lt. Col. (Retd) Dr. Md. Abdul Wahab Professor, Department of Dermatology and Venereology Bangabandhu Sheikh Mujib Medical University, Dhaka.

3. Lt. Col. Dr. Md. Shirajul Islam Khan, MBBS, DDV, MCPS Graded Specialist in Dermatology and Venereology Combined Military Hospital, Dhaka.

4. Dr. Samaresh Chandra Hazra Medical officer Infectious Diseases Hospital, Mohakhali, Dhaka. intracellular bacteria, gram positive, acid and alcohol fast, straight or slightly curved, rod shaped with parallel sides and rounded end, occur in clumps or globi or bundle of cigars in macrophages, only bacteria to infect peripheral nerves, best grow at below human core body temp $320 \mathrm{c}-350 c^{5}$. It can not grow in artificial culture media but may be cultivated in-nine banded armadillo, mouse foot pad, mangabey monkey ${ }^{1}$. The mode of transmission is droplets infection, close contact with the patient for prolong period, ulcerated/abraded skin ${ }^{6}$.

The incubation period is average 2-5 years. In tuberculoid leprosy it is upto 5 yrs and for lepromatous leprosy may be 20 yrs or longer ${ }^{4}$.

\section{Immunopathogenesis of leprosy}

Leprosy is a spectrum disease characterized by a variety of abnormal immune response. It depends on the integrity of the host's specific CMI response to the M. leprae and it may be genetically determined. Whatever may the route of transmission, bacteremia occurs in all forms of leprosy and disseminated throughout the body via blood and lymphatics. M leprae enter the target tissue, selectively schwann cells of peripheral nerves where it multiply and liberate from the infected schwann cells then infect neighbouring schwann cells and thus intraneural infection spreads. The infected nerve is then invaded by histocytes (macrophage) and lymphocytes with subsequent formation of granuloma leading to nerve damage resulting neurological manifestations. If the bodies CMI is capable of anchoring the infection within the nerves without skin involvement this will be limited to pure neural leprosy. But if bacilli or antigens escape from the nerve into surrounding tissue, skin lesions of TT develop at that site. Subsequently borderline leprosy and lepromatous leprosy may develop depending upon the immunity of the individual. Tuberculoid leprosy patient has strong $\mathrm{T}$-cell and macrophage activation with release of type- 1 cytokine (IL-2, IFN-Y and IL-12) which result in CMI response and to localize the infection. In lepromatous leprosy, release of type- 2 cytokine (IL-4, IL-5, IL-10) cause strong antibody response and concomitantly inhibit $\mathrm{T}$-cell and macrophage resulting in progression of the infection ${ }^{4}$.

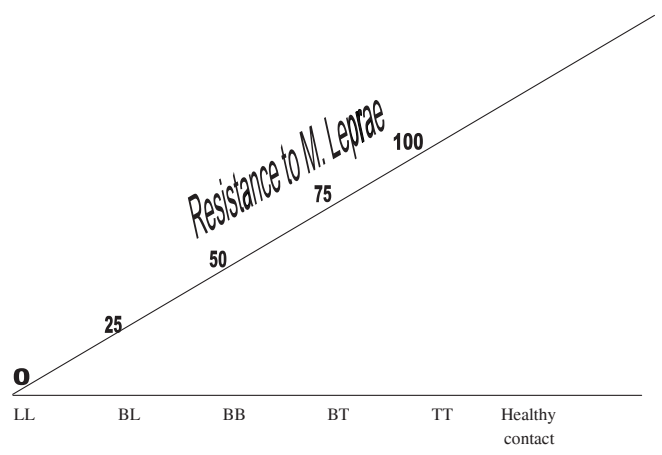

Figure 1: The Spectrum of Immunity in Leprosy ${ }^{1}$. 


\section{Classification of leprosy}

a. Ridlay \& Jopling classification (on the basis of clinical, bacteriological, immunological \& histopathological features):

1) Tuberculoid Leprosy (TT), (2)Borderline Tuberculoid (BT),(3) Borderline Bordrline(BB), (4)Borderline Lepromatous (BL), (5)Lepromatous Leprosy (LL)

b. WHO classification (on the basis of BI/MI):

(I) Paucibacillary leprosy: (a) Tuberculoid leprosy (TT),(b) Borderline tuberculoid leprosy(BT) (c)Indeterminate(I) (d)Pure neural leprosy (PN), where the skin smear is negative and/or the number of Skin lesion(s) are 1-5.

(II).Multibacillary leprosy (a)Borderline leprosy (BB), (b)Borderlinelepromatous(BL)

(c) Lepromatous leprosy (LL), Where the skin smear is positive and/or the number of skin lesion(s) are 6 or more. If a patient is clinically diagnosed as $\mathrm{PB}$, but shows skin smear positivity he/she is classified as $\mathrm{MB}$ and given $\mathrm{MB}$ treatment ${ }^{3}$.

Evolution of leprosy lesion

Negative Contact (M.Leprae-)

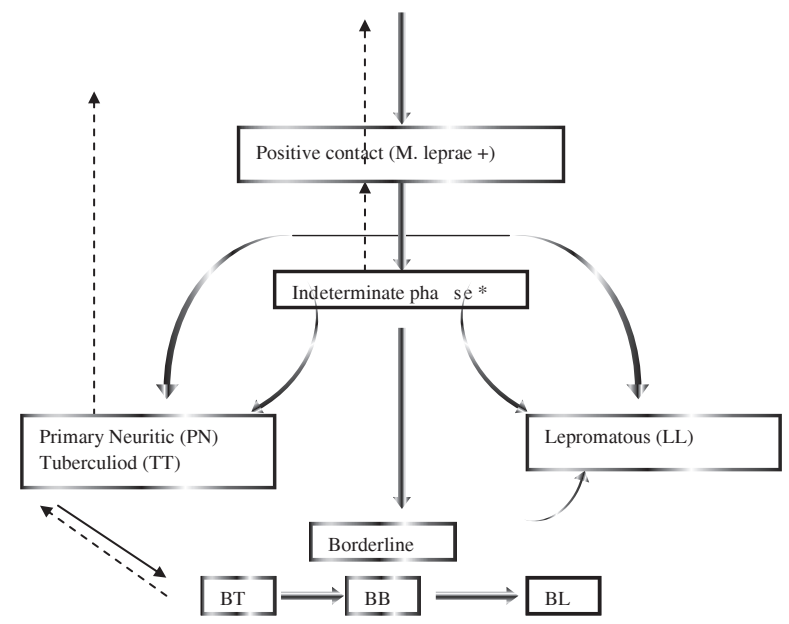

I'Spontaneous reg ression

$$
\text { * Usually an unstable }
$$

Figure II: Evalution of leprosy lesion

\section{Clinical features}

a. Indeterminate leprosy (I): It presents as single or multiple asymmetrical slightly hypo-pigmented or erythematous and usually ill-defined macules on skin, sensation on the affected area is normal or impaired while sweating and hair growth are usually unaffected. The peripheral nerves are not enlarged. Lepromin test may be either positive or negative. It is usually self healing but it may progress to other forms of leprosy ${ }^{7}$.

b. Tuberculoid leprosy (TT): It is usually single or multiple (Less than 5) asymmetrical hypo-pigmented or erythematous, oval or round macules, patches and plaques with a sharply defined elevated border that slopes down to a flattened atrophic center having the appearance of "a saucer right side up". Sensation is markedly impaired or lost, sweating and hair growths are also impaired. Nerve involvement is early and prominent. Peripheral nerves are usually cord like, hard, enlarged and tender. Nerve abscess may occur. Damage to nerves may result in loss of sensation, pain, tingling and muscle weakness or paralysis resulting wrist drop, foot drop, and lagopthalmos. Lepromin test is strongly positive . $^{8}$

c. Borderline tuberculoid leprosy (BT): The lesions are similar to tuberculoid leprosy except these are smaller and more numerous. Satellite lesions around large macules or plaques are characteristic ${ }^{3}$.

d. Borderline leprosy (BB): It is unstable. The lesions are generalized, asymmetrical numerous, hypopigmented or erythematous, irregular shaped plaques. Sensation, sweating and hair growth over the lesions are impaired ${ }^{1}$.

e. Borderline lepromatous leprosy (BL): The lesions are roughly symmetrical, numerous hypopigmented or erythematous macules, papules, plaques or nodules. Sensation and sweating over the lesion-normal. Peripheral nerve involvements appear later, mucosal and systemic involvement usually absent ${ }^{5}$.

f. Lepromatous leprosy ( LL)

(I) skin: The lesions are very numerous symmetrically distributed erythematous or coppery shiny macules ,papules and nodules. The patient may have leonine face, loss of eyebrow and eyelashes (Madarosis). Lepromin test is negative.

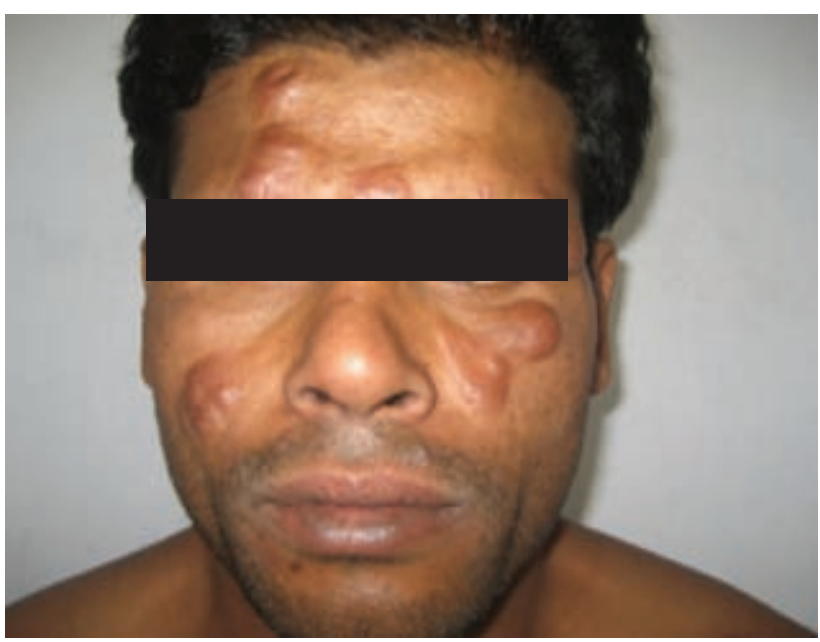

Figure III: Multiple erythematous, indurated, large plaques and nodules on face in a case of borderline lepromatous leprosy.

(II) Nerve involvement: Involvement is bilaterally symmetrical, usually in a glove-stocking pattern. In advance cases nerves become thin and hard due to fibrosis and resulting extensive anesthesia. Nerve changes are-

Sensory - Anaesthesia

Motor - Paralysis and wasting of musles

Autonomic - Loss of sweating and vasomotor dysfunction

(III) Changes in mucous membrane: Nose- saddle nose deformity. Mouth- Perforation of the palate, loss of upper incisor teeth. Larynx- Hoarseness of voice and laryngeal obstruction. 
(IV) Changes in Eye: Corneal erosion, exposure keratitis, ulceration, corneal opacity, vascular keratitis, interstitial keratitis, pannus formation, acute corneal leproma, iritis and iridocyclitis ${ }^{5}$.

(V) Visceral / systemic involvement: Except for the GIT, lungs \& brain virtually every organ may be involved. Lymph nodes, liver, bone marrow, spleen, testicles are heavily infected. Bone marrow of the phalanges is destroyed resulting shortening, osteoporosis and the bone fractures easily. Testes are most commonly \& severely affected resulting testicular atrophy, gynecomastia, azoospermia and sterility. Glomerulonephritis, secondary amyloidosis may occur. Both smooth $\&$ striated muscles are invaded ${ }^{3}$.

g. Special forms of leprosy

(I) Histoid leprosy: Uncommon form of multibacillary leprosy. May found in patient who have discontinued the treatment or leprosy bacilli have become drug-resistant. Erythematous, round or oval, shiny, large papules or plaques and glistening nodules on skin and subcutaneous tissue. Site- Buttocks, lower back, face, and bony prominence. Biopsy shows- elongated or spindle shaped histocytes containing bacilli and showing a whorled arrangement ${ }^{7}$.

(II) Pure neuritic leprosy: Typical nerve damage occur without skin lesion. Ulnar nerve mostly affected. Histology most commonly shows the feature of TT or BL but commonly BT. Sensory change earlier than motor ${ }^{5}$.

(III) Lucio leprosy: This is the special form of lepromatous leprosy found in Western Mexico and certain Latin American areas. It is characterized by a diffuse widespread infiltration of skin (without formation of nodules),loss of body hair, eye brow, eye lashes and wide spread sensory loss. It may smooth the facial wrinkle of older patient resulting youthful appearance, some times called "lepra Bonita" or pretty leprosy".

(IV) Drug resistance leprosy: It is characterized by progressive detoriation in the clinical and bacteriological status of patients inspite of treatment. Two types: Primary resistance occurs in persons who are infected by dapsone resistance M-leprae. May occurs in all types of leprosy. Secondary resistancedevelops as a result of long term monotherapy and it is usually confined to $\mathrm{LL}^{5}$.

\section{Lepra reactions}

It is a tissue destructive, immunologically driven, inflammatory process that may occur in patient of leprosy before, during or after institution of therapy. The triggering factors are institution of multidrug therapy (50\% patient.), intercurrent infections (viral, malaria), anaemia, vaccination, pregnancy and parturition, puberty, drugs-vitamin A, iodides, and bromide, surgical intervention, mental and/ or physical stress. Types of lepra reaction are Type- I Lepra reaction (reversal or downgrading reactions) and Type-II Lepra reaction (Erythema Nodosum Leprosum) ${ }^{3}$.
Type I Lepra reaction (Reversal and Downgrading reaction) :

It is associated with alternation of cell-mediated immune reaction. When cell mediated immunity increase called reversal reaction and when decrease called downgrading reaction. It is a type-IV hypersensitivity reaction usually occurs within 06 months of treatment. It occurs in a borderline spectrum i.e. BT, BB and BL. Some or all the existing leporsy lesions develop pain or tenderness, erythema, oedema, look like erysipelas.Necrosis and ulceration may occur. Affected nerve become rapidly swollen, extremely painful and tender. Nerve abscess may develop. Loss of motor function ie, claw hand, foot drop, facial palsy may occur suddenly. Untreated cases develop permanent paralysis ${ }^{1}$.

Type II Lepra reaction (Erythema Nodosum Leprosum): It is type III hypersensitivity reaction. It occurs almost exclusively in LL, occasionally in BL cases. Existing lesions do not show clinical aggravation. Sudden appearance of crops of evanescent, pink coloured tender nodules or plaques. May become vesicular, pustular, bullous, gangrenous and undergo breakdown. Constitutional symptoms like fever, headache, malaise may develop. Patient may be toxic. It may be associated with- iritis, iridocyclitis, epistaxis, muscle, bone and nerve pain. Epididymo-orchitis, lymphadenitis and proteinuria may develop ${ }^{5}$.

\section{Investigations of leprosy}

a. Blood for complete picture - Anaemia, lymphopenia and increased ESR.

b. Slit skin smear for acid fast bacillus(AFB): Stained films revealed that there were large number of acid and alcohol fast bacilli arranged in straight and curved parallel bundles with globular masses (cigar-bundle appearance), morphologically resembling Mycobacterium leprae.

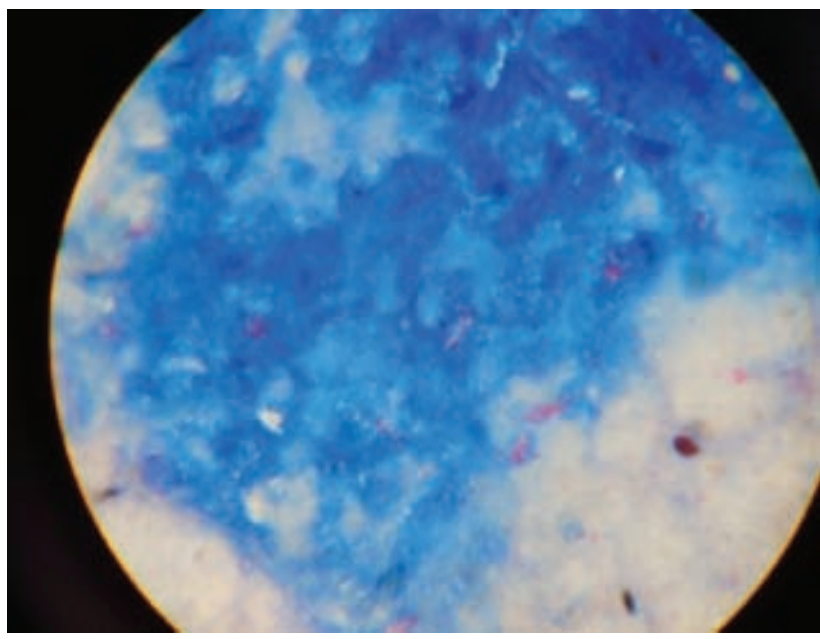

Figure IV: showing findings of slit skin smear for AFB (modified Z- N Stain)

C. Skin biopsy for histopathological examination and FiteFaraco stain: Section from skin revealed extensive infiltration of macrophage in the dermis, separated from epidermis by narrow Grenz zone, with destruction of skin adnexa.Few foci of poorly defined granuloma in dermis is also noted. Large number of lepra bacilli were seen in Wade- Fite stained sections. 

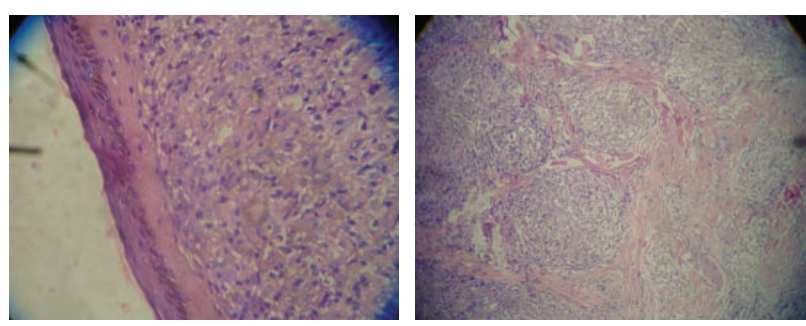

Figure V: showing findings of histopathological examination and Fite-Faraco stain.

d. Peripheral nerve biopsy for histopathological examination. e .PCR test- $50 \%$ +ve in tureculoid type leprosy(TT), negative Polymerase chain reaction(PCR) has no value .f. Serological tests : FLA-ABS(Fruorescent Lepromatous Antibody Absorption test) for detection of M. leprae specific antibodies. RIA-(Radio Immuno Assay) for antibodies to the cell wall antigen of Mycobacterium Leprae. Mycobacterium Leprae Particle Agglutination test(LPA) for antibodies against phenolic glycolipid-1(PGL-I) antigen, ELISA for antibodies against the PGL-I antigen of the cell wall of Mycobacterium leprae. Antibody +ve in $>96 \%$ in LL, $40-50 \%$ in paucibacillary, dip stick test- IgM PGL-I antibody ${ }^{8}$.

\section{Treatment}

Recommended by WHO, 7th expert committee, June 1997 \& National guideline and technical manual on leprosy ${ }^{2}$ :

\begin{tabular}{|c|c|c|c|c|c|c|}
\hline Type & \multicolumn{4}{|c|}{ Monthly supervised dose } & \multicolumn{2}{|c|}{ Self administered Dose } \\
\hline \multirow[t]{4}{*}{ MB cases } & Adults( 15 years +$)$ & Rifampicin & Clofazimine & Dapsone & Clofazimine & Dapsone \\
\hline & & $600 \mathrm{mg}$ & $300 \mathrm{mg}$ & $100 \mathrm{mg}$ & $50 \mathrm{mg}$ daily & $100 \mathrm{mg}$ daily \\
\hline & $\begin{array}{l}\text { Children } \\
\text { years })\end{array}$ & $450 \mathrm{mg}$ & $150 \mathrm{mg}$ & $50 \mathrm{mg}$ & $50 \mathrm{mg}$ alternate days & $50 \mathrm{mg}$ daily \\
\hline & $\begin{array}{l}\text { Children } \\
\text { years) }\end{array}$ & $300 \mathrm{mg}$ & $100 \mathrm{mg}$ & $25 \mathrm{mg}$ & 50mg twice a week & $25 \mathrm{mg}$ daily \\
\hline \multirow[t]{3}{*}{ PB cases } & Adults $(15$ years +$)$ & $600 \mathrm{mg}$ & & $100 \mathrm{mg}$ & & $100 \mathrm{mg}$ daily \\
\hline & $\begin{array}{l}\begin{array}{l}\text { Children } \\
\text { years })\end{array} \\
\end{array}$ & $450 \mathrm{mg}$ & & $50 \mathrm{mg}$ & & $50 \mathrm{mg}$ daily \\
\hline & $\begin{array}{l}\begin{array}{l}\text { Children } \\
\text { years })\end{array} \\
\end{array}$ & $300 \mathrm{mg}$ & & $25 \mathrm{mg}$ & & $25 \mathrm{mg}$ daily \\
\hline
\end{tabular}

Treatment recommendations hansen's disease in united states:

\begin{tabular}{|l|l|l|}
\hline \multicolumn{2}{|l|}{} & $\begin{array}{l}\text { Dapsone 100mg } \\
\text { Daily after MDT for : }\end{array}$ \\
\hline $\begin{array}{l}\text { Paucibacillary } \\
\text { (I,TT,BT) }\end{array}$ & $\begin{array}{l}\text { Dapsone 100mg daily plus } \\
\text { Rifampicin 600mg daily for 6 } \\
\text { months }\end{array}$ & $\begin{array}{l}\text { 3 years (I and TT) } \\
5 \text { years (BT) }\end{array}$ \\
\hline Multibacillary(BT,BL,LL) & $\begin{array}{l}\text { Dapsone 100mg daily plus } \\
\text { Rifampicin 600mg daily for 3 } \\
\text { years }\end{array}$ & $\begin{array}{l}10 \text { years(BB) } \\
\text { Lifelong (BL,LL) }\end{array}$ \\
\hline
\end{tabular}

\section{Treatment of lepra reaction}

General measures-Both physical and mental rest. Should continue antileprotic drugs.Anti inflammatory therapy-Aspirin or NSAID.

Type 1 reaction- Systemic corticosteroid 40-60mg/day, 3-4 months then slow taper, Clofazimine-300mg/day, Cyclosporine- $5-10 \mathrm{mg} / \mathrm{kg}$ starting dose. (if steroid fail).

Type 2 reaction- Thalidomide- Is the drug of choice, $400 \mathrm{mg}$ daily until the reaction is controlled, and then reduced gradually to $50 \mathrm{mg}$ daily, Systemic corticosteroid $0.5-1$ $\mathrm{mg} /$ day, Clofazimine in higher dose (300mg/day), Pentoxyphylline \& clofazimine combination can be used when thalidomide $\&$ steroid cannot use ${ }^{3}$.

\section{Complications of leprosy}

Due to nerve damages-claw hand, wrist drop, foot drop, lagopthalmos and due to massive invasion of tissues by $\mathrm{M}$. leprae-iritis, iridocyclitis, testicular atrophy, gynaecomastia, epididymoorchitis, leonine facies and saddle nose. Other complication is malum performance pedis ${ }^{5}$.

\section{Prevention \& control}

a. Case detection and prompt treatment.

b. Immunoprophylaxis by BCG vaccination and a heat killed M. leprae plus BCG vaccination.

c. Improvement of living condition.

d. Health education and proganda about leprosy ${ }^{1}$.

\section{Rehabilitation}

To reintegration of the leprosy patient into the community, taking part in all its activities as a contributing member of the society $^{2}$.

Leprosy is the most ancient bacterial disease in the history of mankind. It remains still public health problem in the countries where it is endemic. Antileprotic multidrugs therapy (MDT) as recommended by WHO is now the standard and accepted method for leprosy control. Leprosy can not be completely rooted out with physicians, control offices, leprosaria and propaganda; it will disappear when the economic and cultural factors change, because leprosy is the thermometer of civilization.

\section{References}

1. Jopling WH, McDougall AC. Handbook of Leprosy. 4th edition.London: Heinemann Professional Publishing. 1988;18-45.

2. National Guidelines and Technical Manual on Leprosy. 3rd edition. World Health Organization. 2005.

3. James WD, Berger TG and Elston DM. Andrews' Disease of the skin Clinical Dermatology.10th edition. USA: Saunders Elsevier. 2006;343-352.

4. Wolff K, Goldsmith LA, Katz SI, Gilchrest BA, Paller AS and Leffel DJ. Fitzpatrick's Dermatology in General Medicine. 7thedition. New York: McGraw Hill Companies. 2008;1786-1796

5. Hastings RC. Leprosy. 2nd edition. New York: Churchil living stone. 1994;51-78.

6. Wolverton SE. Comprehensive Dermatologic Drug Therapy. W.B Saunders Company. 2001;230-250.

7. Madhusudan M. Leprous neuritis: A diagnostic dilemma. Indian Journal of Dermatology, Venereology and Leprology. 2009;65:59-65.

8. Kaimal S, Thapa. Relapse in leprosy. Indian Journal of Dermatology, Venereology and Leprology. 2009; $75: 126-135$. 